\title{
1-2-3-4! Measuring the values of live music: methods, models and motivations
}

\author{
Arno van der Hoeven \\ Erasmus Research Centre for Media, Communication and Culture, \\ Erasmus University Rotterdam, The Netherlands \\ Adam Behr \\ Newcastle University, Newcastle upon Tyne, UK \\ Craig Hamilton \\ Birmingham City University, Birmingham, UK \\ Martijn Mulder \\ Erasmus Research Centre for Media, Communication and Culture, \\ Erasmus University Rotterdam, The Netherlands, and \\ Patrycja Rozbicka \\ Aston University, Birmingham, UK
}

\begin{abstract}
Purpose - This paper sets out to compare different methodologies for measuring the value(s) of live popular music and to explore the different motivations amongst a range of organisations engaged in that work.

Design/methodology/approach - The authors analyse how the values of live music are measured, who does it and why. Based on this analysis the authors present a model that visualises the myriad of organisations, methods, aims and objectives involved.

Findings - The authors identify three approaches to measuring the impact of live music (economic impact studies, mapping and censuses and social sciences and humanities) and three types of actors (industry, policy and academia). The analysis of these demonstrates that measuring live music is not a neutral activity, but itself constructs a vision on how live music ecologies function

Practical implications - For cultural organisations, demonstrating the outcomes of their work is important in acquiring various forms of support. The model presented in this paper helps them to select adequate methodologies and to reflect on the consequences of particular approaches to measuring live music activities.

Originality/value - While the number of studies measuring live music's impact is growing, theoretical and methodological reflection on these activities is missing. The authors compare the different methodologies by discussing strengths and weaknesses. This results in a model that identifies gaps in existing studies and
\end{abstract}

(c) Arno van der Hoeven, Adam Behr, Craig Hamilton, Martijn Mulder and Patrycja Rozbicka. Published by Emerald Publishing Limited. This article is published under the Creative Commons Attribution (CC BY 4.0) licence. Anyone may reproduce, distribute, translate and create derivative works of this article (for both commercial and non-commercial purposes), subject to full attribution to the original publication and authors. The full terms of this licence may be seen at http://creativecommons.org/licences/by/4.0/ legalcode

This work was supported as part of the project Staging Popular Music: Researching Sustainable Live Music Ecologies for Artists, Music Venues and Cities (POPLIVE) established by the Dutch Research Council (NWO) and the Taskforce for Applied Research (NRPO-SIA) [grant number 314-99202, research programme Smart Culture - Arts and Culture]. Partners in this project are Mojo Concerts and the Association of Dutch Pop Music Venues and Festivals (VNPF). The work was also supported by the Creative Industries Policy and Evidence Centre (PEC), which is led by Nesta and funded by the Arts and Humanities Research Council UK.

Measuring the values of live music
Received 30 September 2020 Revised 27 November 2020 15 December 2020

13 January 2021

21 January 2021

22 January 2021

Accepted 22 January 2021 
explores new directions for future live music research. It enhances understanding of how different ways of measuring live music affect policymaking and conceptions of what live music is and should be.

Keywords Live music, Economic impact studies, Cultural value

Paper type Research paper

\section{Introduction}

As soon as live music activities ceased following the outbreak of the COVID-19 pandemic, actual measurement of live music's impact gained in prominence. Studies on live music's sociocultural and economic relevance were vital for this sector in order to qualify for government support and to understand the financial consequences of the lockdown (see for example: HoC, 2020; Musicians Union, 2020; and, UK Music, 2020). These types of studies build on a long history of public and private research on live music. Over the last decades, the attention to measuring cultural activities had already grown because of evidence-based policymaking and the calls on cultural organisations to prove their relevance to society (Gielen et al., 2014; O'Brien, 2010). These measures are expected to legitimise the investment of public resources such as subsidies and spaces (Getz et al., 2017; Wall, 2008).

This paper sets out to compare different methodologies for measuring live music's values and to explore the different motivations amongst a range of organisations engaged in that work. In doing so, we focus on popular styles of live music, while acknowledging that the boundaries between popular music and, for example, classical music are not always easy to draw. We understand live music as events "in which musicians (including DJs) provide music for audiences and dancers gathering in public places where the music is the principal purpose of that gathering" (Webster et al., 2018, p. 115). The values of these events concern their potential impact and benefits for people, communities and places. This includes, among others, social, cultural and economic values. The actors involved in measuring the values of live music include not only those involved with the business of music, but local and national government agencies and policy makers and also companies such as property developers linked to business planning. While the number of studies measuring live music's impact is growing, theoretical and methodological reflection is missing. By comparing the motivations and methodologies of different actors, we gain a better understanding of how different ways of measuring live music affect policymaking and conceptions of what live music is and should be. We aim to build bridges between diversified organisations to help them to understand the limitations, challenges and opportunities of their approaches, and where they may benefit from a cross-contamination of methodologies.

This paper presents measuring live music's impact as a complex, multi-faceted phenomenon. We argue that measuring live music is not a neutral activity, but itself constructs a vision on how live music ecologies should function. If live music ecologies are understood as the network of people and organisations enabling musical performances, this implies that those actors who engage in measuring live music are actors in this ecology. In fact, data-derived services (e.g. Songkick, Skiddle) engage in live music measurement as part of their business models. Measurements of live music activity feedback into how live music ecologies function and are organised. For example, when measures emphasise the economic impact of live music, it is likely that policymaking will be directed towards these economic goals. Furthermore, if particular methodologies are incomplete in their measurements, this could lead to oversights in decision-making.

The paper consists of three sections. First, we examine how live music is measured by discussing a range of methodologies (e.g. mapping, censuses and economic impact studies) and data sources (i.e. qualitative and quantitative). Second, we explore who does the measuring, distinguishing actors in the fields of industry, academia and policy. Third, we present a model to compare different approaches, reflecting on their commonalities, tensions 
and gaps. This model can serve as a resource for those planning new research projects on the impact of live music. We conclude by discussing potential new methodologies and approaches to measuring live music's impact. We draw on the experiences of measuring live music gained in projects from the Netherlands and UK: Staging Popular Music (POPLIVE), [1] Birmingham Live Music Project (BLMP) [2] and the UK Live Music Census [3].

\section{How is live music measured (and what does it tell you)?}

In this section, we present three approaches to measuring live music, each generally having different aims and forms of data (Table 1). We distinguish economic impact studies, mapping and censuses and a social sciences and humanities approach. It should be noted that the studies we cite are not exhaustive rather they are indicative types of measuring.

\begin{tabular}{|c|c|c|c|c|c|}
\hline \multirow{2}{*}{$\begin{array}{l}\text { Perspectives } \\
\text { Economic } \\
\text { impact studies }\end{array}$} & \multicolumn{2}{|c|}{ Aims } & \multicolumn{2}{|c|}{ Data and Method } & $\begin{array}{l}\text { Who or what is } \\
\text { measured }\end{array}$ \\
\hline & $\begin{array}{l}(1) \\
(2)\end{array}$ & $\begin{array}{l}\text { Understanding the } \\
\text { economic impact of live } \\
\text { music } \\
\text { Understanding the } \\
\text { contribution of live music } \\
\text { to the attractiveness of } \\
\text { places }\end{array}$ & $\begin{array}{l}(1) \\
(2) \\
(3) \\
(4)\end{array}$ & $\begin{array}{l}\text { Cost benefit analysis } \\
\text { Andersson et al. (2012), } \\
\text { Carter and Muller (2015), } \\
\text { Propheter (2015) } \\
\text { Contingent valuation } \\
\text { O’Brien (2010) } \\
\text { Hedonic pricing Garretsen } \\
\text { and Marlet (2017) } \\
\text { Box office statistics } \\
\text { Connolly and Krueger } \\
\text { (2006), Krueger (2019) }\end{array}$ & $\begin{array}{ll}\text { (1) } & \text { Economic } \\
& \text { value } \\
\text { (2) } & \text { Consumers } \\
& \text { expenditure } \\
\text { (3) } & \text { Employment } \\
\text { (4) } & \text { Venues as } \\
& \text { amenities } \\
\text { (5) } & \text { Revenues }\end{array}$ \\
\hline $\begin{array}{l}\text { Mapping and } \\
\text { censuses }\end{array}$ & $\begin{array}{l}(1) \\
(2) \\
(3)\end{array}$ & $\begin{array}{l}\text { Taking stock } \\
\text { Spatial analysis } \\
\text { Needs assessment }\end{array}$ & $\begin{array}{l}\text { (1) } \\
\text { (2) } \\
\text { (3) }\end{array}$ & $\begin{array}{l}\text { Geographic information } \\
\text { systems (GIS) Cohen } \\
(2012 b) \\
\text { Surveys Behr et al. (2019) } \\
\text { Hand-drawn maps Cohen } \\
\text { (2012a) }\end{array}$ & $\begin{array}{ll}\text { (1) } & \text { Stages } \\
(2) & \text { Cities } \\
(3) & \text { Concerts }\end{array}$ \\
\hline $\begin{array}{l}\text { Social sciences } \\
\text { and humanities }\end{array}$ & $(1)$ & $\begin{array}{l}\text { Understanding live } \\
\text { music's impact on people, } \\
\text { communities, health and } \\
\text { wellbeing }\end{array}$ & $\begin{array}{l}(5) \\
(6) \\
(7) \\
(8)\end{array}$ & $\begin{array}{l}\text { Surveys Willekens and } \\
\text { Daenekindt (2020) } \\
\text { Diaries Behr et al. (2016), } \\
\text { Everts et al. (forthcoming) } \\
\text { Social Network Analysis } \\
\text { Crossley and Emms (2016), } \\
\text { Mercado-Celis (2017) } \\
\text { Focus-groups Packer and } \\
\text { Ballantyne (2011) and } \\
\text { interviews Mulder et al. } \\
\text { (2020), Raine (2019) } \\
\text { Ethnography Webster } \\
\text { (2011) } \\
\text { Archival research and oral } \\
\text { histories Southall (2016) } \\
\text { (social) media analysis } \\
\text { Bennett (2012), Danielsen } \\
\text { and Kjus (2019) } \\
\text { Workshops and } \\
\text { consultations, co- } \\
\text { production of knowledge } \\
\text { BLMP Wall (2008) }\end{array}$ & $\begin{array}{ll}\text { (1) } & \text { Audiences } \\
\text { (2) } & \text { Musicians } \\
\text { (3) } & \text { Musical } \\
& \text { professionals } \\
\text { (4) } & \text { Communities } \\
& \text { (e.g. scenes) } \\
\text { (5) } & \text { Ecologies } \\
(6) & \text { Cities }\end{array}$ \\
\hline
\end{tabular}

Social sciences and humanities
Measuring the values of live music

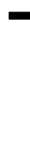


Furthermore, in practice the three categories can overlap. For example, economic impact studies or mapping projects are sometimes conducted by scholars in the social sciences and humanities.

\subsection{Economic impact studies}

Economic impact studies focus on direct and indirect financial benefits of live music. In those, live music is perceived as being part of the market (Klamer, 2004; Angelini and Castellani, 2018), implicating a focus on costs and (economic) benefits. In the existing literature, several approaches can be distinguished, based on scope, focus and type of analysis. The scope of these studies is predominantly on a national or state-level or city level; economic impact measurement on the level of specific venues is scarce. The focus of impact studies can be either internal (measuring the value of live music within the music industries, see for example Holt, 2010; Krueger, 2019) or external (measuring the added value of live music to the economy in general). Furthermore, two types of analysis can be distinguished: measuring direct economic impact (e.g. revenues) and measuring indirect economic effects (e.g. secondary expenditures).

A large proportion of the existing literature aims to map the external direct economic impact on a national or city level. These studies predominantly measure the gross added value of live music to the national GDP and use several variables, including revenues, boxoffice figures, concert pricing, visitor expenditure, employment and artist fees (see for example: UK Music, 2019). Methodologically, these contributions rely both on existing data (such as ticket sales or Pollstar data) and conventional research methods such as surveys and, to a lesser extent, interviews. The outcomes are generally presented as an estimated total of gross value added, total expenditure, employment figures, or as an input-output ratio. Measuring the added value of live music to the economy has several disadvantages: live music is not a well-defined industry (meaning that different studies use different definitions); gathering data relies heavily on the cooperation of the industry; most studies put an emphasis on the benefits of live music and lack a comprehensive cost-analysis; outcomes are frequently based on extrapolations of available data; there is too little attention for substitute effects (e.g. new venues opening in a city, use of alternative, user friendly technologies); and the majority of these studies appear to lack specific data such as secondary ticketing revenues or input from (underground, informal) grassroots supply. Moreover, information collection omits study of wider population ecologies (including actors involved in venue maintenance, hospitality contractors and service providers) and dismisses impact on supply chains. A final remark here is that most studies that measure the economic effects of music festivals are grounded in tourism research and consequently measure visiting festivals as part of the total tourist expenditure.

Measuring indirect economic effects, alongside attempts to monetise non-economic effects, is a growing field in studies of the economic impact of live music. These indirect effects are measured as immediate spin-off effects (secondary expenditure or multiplier-effect, derived employment), future spin-off effects (image-building, gentrification), substitute effects (crowding out), indirect user values (consumer surplus / contingent value) or non-use values. The latter define live music supply (venues, arenas, festivals) as an amenity in general and value either the willingness to pay for maintaining cultural supply even though the consumer has never used the supply (option value) or the willingness to preserve the cultural supply for future generations (bequest value). In several economic impact studies, especially those which focus on a city level, the secondary expenditure is estimated based on live music visitor surveys (often exemplified as "music tourists", albeit defined in a wide range of ways). Insights in future, non-use and substitution effects are equally gathered through consumer surveys, although these effects are generally not quantified in the research outcomes. 
Concluding, many studies on the economic impact of live music emphasise the difficulties in presenting reliable estimations of this impact, as well as the complexity of the live music industry. This supports the idea that cultural markets differ from other markets and cannot be adequately explained by classic economics (Holt, 2010; Velthuis, 2005) and that more than economic values are at stake in the provision of cultural goods (Klamer, 2004). Finally, in economic live music research, there appears to be a shift in what is measured, moving from purely economic indicators to more socio-economic data and cultural impact.

\subsection{Maps and censuses}

Maps and censuses aim to produce an inventory of live music activities in a circumscribed geographical area. This allows a spatial analysis of where live music takes place, provides insight into the amount of activity and enables the identification of gaps in music provision.

This includes, to give a simple example, the Seattle Music Map [4], which highlights locations linked to the status of Seattle as a City of Music. A more elaborate example is the Seattle Band Map [5] exploring the region's music scene through tracking the interconnectedness of bands across personal relationships and collaborations. Mapping activities have benefited from advances in Geographical Information Systems and crowdsourcing techniques (Mattioli, 2014). Over the years, digital tools to plot data on maps have become more accessible and user-friendly, leading to a plethora of activity by both commercial and non-commercials actors. Many mapping activities have their roots in research taking place at universities. For example, the BLMP produced an interactive online map of music venues in the city of Birmingham, the UK. Methodologically, this work combined the web-scraping of commercial data with crowd-sourced information, augmented by stakeholder surveys and publicly available data linked to postcodes and other geographical variables.

Live music censuses typically provide a snapshot of live music in a particular place and time window. For example, the UK's first national live music census, which took place in 2017, recorded live music activity across a 24-h period in three localities (Behr et al., 2019). It was conducted by volunteers who visited venues to collect observational information and conduct surveys of audience members and staff. The initiators of the UK national live music census stress it is not just an "academic exercise" (Behr et al., 2019, p. 1): "It has potential for impact on how policymakers - locally, nationally, and internationally - understand, value, and encourage live music in cities."

Mapping and census exercises provide unique insights into geographical spreads of live music, informing urban development plans (Behr et al., 2019), niche areas requiring funding and suggested directions for cultural policy investments (Wall, 2008). However, they are highly dependent on response rates, willingness of participants to provide information (i.e. crowdsourcing) and the assembly of a representative sample.

\subsection{Social sciences and humanities approaches}

The final category of social sciences and humanities approaches (SSH from now on) seeks to understand live music's impact on people, communities, health and wellbeing. This approach aims to enhance our knowledge of live music's role in society. Compared to economic impact studies, this entails a stronger emphasis on the socio-cultural meanings of live music for participants. Where in economic impact studies live music is perceived as a market product, in SSH the emphasis lies on live music as a manifestation of culture. Most SSH measurement here has a largely positivist approach, but researchers also operate in a more critical strand of popular music studies. The latter includes work that uses ethnography to give a voice to marginalised communities and to address gender imbalances (Raine, 2019; Lashua and 
Cohen, 2010; Bain, 2019). Generally, studies in the SSH approach rely on conventional qualitative (e.g. interviews and ethnography) and quantitative (e.g. surveys) research methods. Furthermore, historical studies draw on oral histories and archival research to understand live music's impact in the past. Increasingly, these conventional methods are supplemented with more advanced techniques and data sources following methodological and technological innovations. This includes the use of Social Network Analysis to understand the connections between various actors in "music worlds" (Crossley and Emms, 2016; Berry, 2011), analysis of streaming and social media data to gain insight into online audience activity (Bennett, 2012; Danielsen and Kjus, 2019), and reflective diaries adding understanding of how music professionals go about their work and how audiences experience live music (Behr et al., 2016).

In terms of what is measured, all three approaches generally take cities, states or countries as starting points. Within this geographical scope, economic impact studies focus on consumers and financial benefits, mapping and censuses on venues and concerts, and the $\mathrm{SSH}$ approach has a stronger emphasis on the various participants in live music ecologies (e.g. musicians and fans). However, all three approaches must deal with issues of measurement and definition that have an impact on their findings. As Raine (2019, p. 18) observed in her work around 50/50 gender balance in festival line-ups, a loose interpretation of how such a balance should be defined presented issues for accurate data gathering. Elsewhere, in industry-led studies such as UK Music's "Wish You Were Here" reports into UK music tourism $(2015,2017)$, methodological definitions are inherently fluid since they are subject to changes in geographical boundaries and average community distances defined by external bodies such as the Office for National Statistics, which may change from one reporting period to another. More broadly, questions and assumptions regarding the objectivity of data in and of itself have been raised by Gitelman (2013) and others. In short, a consideration of the decisions (practical, political or otherwise) around how data categories and measurements are defined is as important as the collection and analytical phases in measurement projects. In the next section we will further examine the politics of this, by discussing the different actors and their motivations

\section{Who does it (and why)?}

The second part of our analysis consists of an overview of the different actors who measure live music, what reasons and motivations they have and which of the aforementioned approaches they use. We identify three groups of actors measuring live music: the music industry, academics and policy makers.

\subsection{Industry}

Various organisations seek to represent the interests of the live music sector. They are key actors in measuring live music from an industry perspective. These include national trade institutions and representative bodies like UK Music, the Dutch Association of Pop Music Venues and Festivals and PopNL (a cooperative of local artist associations), their equivalents in other countries and international networks such as Live DMA, the European Festivals Association and the European Federation of Music and Live Performance Organizations (Pearle*). In many cases, industry bodies cooperate with commercial research agencies (e.g. Sound Diplomacy in the UK and Significant APE in the Netherlands). This is particularly the case in the Netherlands, where industry-commissioned research is generally conducted by commercial agencies, not by academics.

A large proportion of industry research aims to gain insight into key metrics (visitors, expenditures, employment) to assist the development of business models and marketing 
campaigns. On a national or city level, industry-commissioned studies often focus on measuring economic impact, legitimisation of industry (and its funding) and accountability. Here, the research agenda is closely linked to the subject of policymaking, as we discuss later. Many industry studies make use of (audience and artist) surveys, stakeholder interviews and existing data from within the industry (e.g. VNPF 2018; UK Music 2019).

Industry-commissioned reports provide an opportunity for the various sectors to take regular stock of their situation. But, they also serve as a tool for lobbying - and interacting with - government, representing the interests of the various - and sometimes competing music industries. As Williamson and Cloonan point out (2007), the music industries are a variegated group of interests (publishing, recording, live music and so on) and often best thought of in the plural, rather than as a monolithic whole. Nevertheless, trade body reports that cover a range of activities work towards the goal of inculcating in policymakers a general awareness of music's economic value and a sense of specific business concerns (such as those around planning and urban regeneration) at a given point in time.

\subsection{Academic approaches}

Academic live music research is embedded in several fields of study, which deploy varying approaches. Much of this is accommodated in departments of media, culture and arts, sociology, economics, business and policy. In media, culture and sociology, the social sciences and humanities approach generally predominates. In these fields, research aims to understand (1) live music behaviour (preferences, motivations, experiences and group behaviour), (2) live music as an artistic and cultural practice (critical studies, talent development, musicology, artistic practice) and (3) the field of live music in general (scenes, networks and ecologies). In economic departments, research focuses primarily on the internal economic impact of live music. Economists such as Krueger (2019) and Mortimer et al. (2012) contribute to the understanding of live music's value in relation to recorded music. From a business and marketing perspective, relevant contributions include studies on branding, brand equity, customer equity and hedonic consumption (e.g. Garretsen and Marlet, 2017; Leenders, 2010) and business modelling in general (Naveed et al., 2017). These contributions draw on (visitor) surveys, interviews and existing data sources such as Pollstar.

Academic research on live music contributes both to theory development and knowledge utilisation. The latter is becoming increasingly important. In the Netherlands, for instance, the Dutch Research Council stimulates researchers to cooperate with key industry stakeholders. For example, a funding requirement for the POPLIVE project was that industry actors co-fund the project. In the UK, likewise, "Knowledge Exchange" between academic, industry and policymakers is an important part of the research landscape. Indeed, the national audit of research - the Research Excellence Framework - takes account of "impact" outside the academy as a key strand of its assessment. This is reflected in funding calls and funding bodies. The BLMP was supported by the "Policy and Evidence Centre", run by innovation foundation NESTA and funded by the Arts and Humanities Research Council. Preliminary research in Birmingham (Rozbicka et al., 2019) deployed workshops with industry stakeholders as a means of co-producing knowledge about the challenges facing the live sector from Brexit and, latterly, COVID-19. Academic work, then, exists in a feedback loop with industry bodies and personnel, drawing on industry reports and sources at the same time as seeking to inform them.

In a competitive funding environment, demonstrable potential for the co-production of knowledge and uptake of research findings beyond the academy provide an incentive beyond the pedagogical for interactions with industry. This is not to suggest that such initiatives are purely tactical. Academics respond, of course, to the exigencies of their funding frameworks, where focus is on creation of impact and added value of the research (Belfiore, 2002), and
Measuring the values of live music

$+$


partnership with the industry can help with that. But "impact" can also be viewed as a means of supporting the live music ecologies that are simultaneously the subject and the context of their research. There are tensions in terms of power relations across the academy, industry, musicians and audiences (Williamson et al., 2011). Amongst these are the questions of how to frame the problems and opportunities in play and how to balance the economic concerns and framing devices - of industry against broader, but less easily quantifiable, questions of cultural value and intrinsic goods (Crossick and Kaszynska, 2016). The two are not mutually exclusive, however, and as well as tensions and the potential for "knowledge resistance" when academic findings cut across industrial concerns and understandings (Williamson et al., 2011), there are also synergies, as both academics and industry face towards policymakers, who are both users and producers of live music research. Further, as Belfiore and Bennett (2010) suggest, we may need a new "toolkit" for impact evaluation, which moves us beyond purely economic benefits and focuses on intrinsic socio-cultural value of live music.

\subsection{Policy}

Measuring the values of live music from a policy perspective takes place on several geographic levels, from local (urban or regional) to national and even global (such as UNESCO's Festival Statistics Report, 2009). Policy research is often characterised by a strategic, long-term and holistic approach. Key actors here are ministries/departments, government bodies and commissioned research agencies. Again, these different categories are not mutually exclusive. Local and national government bodies, like industry, may commission research agencies and, indeed industry organisations. The Greater London Authority's "Grassroots Music Venues Rescue Plan" (2015) was produced by its "Music Venues Taskforce", which contains members of industry representative bodies like the Music Venue Trust, Musicians' Union and UK Music, as well as the authority's officers. Academics feed into the process as well. Longstanding debates, including lobbying about secondary ticketing (Behr and Cloonan, 2018), drove the inclusion of a mandate in the UK's 2015 Consumer Rights Act for an enquiry into the secondary market, which was produced for the Department of Business, Innovation and Skills by academic economist Professor Mike Waterson (Waterson, 2016).

Academic and industry research, together and separately can also feed into the policy process as it plays out in the interactions between different arms of the policy realm. For example, the UK's Parliamentary committee - part of the legislature - responsible for oversight of the governmental Department of Digital, Culture, Media and Sport - the executive - responded to public campaigning, media coverage and related public concern to launch an enquiry into the state of live music in the UK (HoC, 2019). This took soundings from the public, industry bodies and drew on academic research, including the UK Live Music Census (Behr et al., 2019) which had been conducted by academics partnered with industry.

Policy bodies, like the different sectors of industry and different academic fields, have concerns that vary both geographically, from local to national to international and departmentally. Culture or finance ministries, and those responsible for planning and local government, may have different and cross-cutting priorities with countervailing effects on live music provision. Notwithstanding an oft-stated desire for evidence-based policies (Gielen et al., 2014, pp. 30-31), the range of uses to which evidence is put and the frames within which it is deployed may shift according to the needs of a particular governmental or arms-length organisation. Mapping, economic-impact studies and the qualitative responses of stakeholders form a menu from which they can draw. In any case, as the above examples demonstrate, the users and producers of live music research are heavily intertwined. 


\section{Exploratory model}

So far, we have considered how live music's value(s) can be measured, who engages in measurement and what the motivations are for measurement. From this it is clear that the landscape is complex and - as the COVID crisis starkly reveals - subject to external factors that can bring about rapid change. From here, we want to move to ask the question of how or whether the activities, actors and motivations outlined can themselves be understood ecologically, and if so - what it can reveal about not only existing research, but also the potential for new areas of collaboration. We suggest that developing new ways of performing live music measurement may help ameliorate some of the issues discussed earlier. Studies emphasising the economic impact of live music, for example, often elide questions of cultural value and vice versa. Likewise, a national focus often cannot account for localised concerns and activities.

Alongside this, there are other activities - and, indeed, communities associated with them - that do not easily lend themselves to measurement, with the consequence that even the most methodologically robust measurement study will render them invisible. Those include free gigs, "underground" shows where tickets are sold at the door, live music at weddings, busking and performances in venues that do not count visitors. In fact, measuring impact requires resources like time and money, which are scarce for many organisations as they need to focus on their main cultural objectives (Behr et al., 2016; Holden, 2004). Furthermore, it should be noted that if effects are not or cannot be measured, this does not necessarily mean that they do not exist. Gielen et al. (2014) highlight the risk that evidence-based cultural policies could lead to forms of decision-making that only support practices which can be easily measured. While the number of people that attend concerts can relatively easily be quantified, this is more difficult - not to say impossible - for the intrinsic value of music.

A separate, although related, question resides in the implication that if live music ecologies can be measured, they can also be controlled or guided through design and intervention. Our overview of ways of measuring and actors involved in this activity reflects a growing attention to evidence-based policies. This is a consequence of - among other things $-\mathrm{a}$ neoliberal focus on accountability (Dyndahl, 2013), in which cultural organisations are expected to prove their relevance and impact. Holden (2004) observes this might lead to a bureaucratisation of culture, with funders becoming more prescriptive for how cultural organisations should work.

In an attempt to engage with these issues, and based on our - by no means exhaustive survey and discussion of existing activities, we now present an exploratory model for categorising, understanding and developing live music measurement that, we suggest, can begin to account for the myriad of organisations, methods, aims and objectives involved, which may assist in addressing the broader set of concerns outlined above. The model comprises two key elements: Categories and Scale. These are explained in more detail below (Table 2). Each of the six categories (data collection methods, geographical focus, motivation, focus, funding and actors) contains sub-sections categorised according to a scale ranging from 0 to 4 . The word "scale" here is not in and of itself a measurement of relative value. Rather, we deploy scale to categorise projects as a whole and to map out a wide array of activities, actors, motivations and locations. In the case of Data Methods activity, the scale relates to the extent that a particular project engages in one or more broad types of data collection, whereas for the Actors element, the scale shows the extent to which different groups of people perform the research, either in isolation or collaboration. Similarly, for Motivations, activity is denoted by the extent to which it is aligned towards one or more of a particular set of goals.

By combining the different categories, sub-categories and scales described in Table 2, projects measuring live music can be visualised according to the model shown in Figure 1. Sub-categorical allocations across six groups can be visualised using a radar chart, which can be used to generate a basic "footprint" of projects to be used for evaluative and comparative purposes.
Measuring the values of live music 
Categories

Data methods

How is the data collected?

Quantitative

Measurement activity counts figures, categories and metrics

Qualitative

Measurement activity gathers and analyses long-form, descriptive data, such as interviews

Geographic

Where the measurement activity takes place?

Focus

Local

National

Measurement activity focussed on a specific area within a country, be it a single city or a region

within a single country

International Measurement activity focused on more than one country, providing cross-border comparisons

\begin{tabular}{ll}
\hline $\begin{array}{l}\text { Motivations } \\
\text { Knowledge }\end{array}$ & $\begin{array}{l}\text { Why the measurement activity is undertaken? } \\
\text { Produces new knowledge for a given academic field, likely related to theoretical and/or } \\
\text { methodological intervention } \\
\text { Produces new knowledge intended for, or for the benefit of, a particular set of economic } \\
\text { activities. These may be directly related to live music (e.g. ticket sales) or may be associated } \\
\text { with tangential activity (e.g. housing developments) } \\
\text { Influences/supports/informs lobbying activity at local/national/international level }\end{array}$ \\
Policy & $\begin{array}{l}\text { What the measurement activity focuses on (the location of intended benefit/beneficiaries for a } \\
\text { particular measuring activity)? }\end{array}$ \\
\hline Research foculating economic activity \\
Economic & $\begin{array}{l}\text { Documenting/influencing/stimulating ecolich } \\
\text { Documenting/understanding/theorising cultural meaning (aesthetic, symbolic and } \\
\text { narrative value of live music) }\end{array}$ \\
Social & $\begin{array}{l}\text { Documenting/contextualising/theorising societal factors (looking impact of live music on } \\
\text { people, health, wellbeing, communities and individual development) }\end{array}$ \\
\hline
\end{tabular}

Funding sources Who pays for the measurement activity?

Public Funded by local councils, charitiesetc.

Private Funded by industry / commercial interest groups

Research $\quad$ Funded by Universities or research councils

Actors Who undertakes the measurement activity?

Academic Academic researchers

Industry Commercial organisations and trade bodies

Civic Government, Charities, Local Councils

Scale

Key Description and examples

0 - None at all Does not factor at all in this measurement activity (example: UK Music research is not

funded by research council; BLMP does not have an international focus)

1 - Minor $\quad$ Forms a small part of this measurement activity, but one or both of the other elements are more important (example: BLMP collects some economic data; BLMP has some

2 - Mixed/equal Is on a largely equal footing with one or both of the other two elements in this section

(example: Live Music Census gathers quantitative and qualitative data)

3 - Major Forms a major part of this measurement activity, but one or both of the other elements are also present (Example: UK Music mainly focussed on quantitative data; BLMP aims to inform/support lobbying/policy and produce new academic knowledge, but not research for commercial purposes)

Table $2 . \quad 4$ - Total

Exploratory model metrics The element represents the vast majority of focus. Some other elements may also be represented, but only in a minor role" (example: UK Music is funded by commercial interest groups)

As part of testing of our proposed model, we allocated values to three academic research projects: BLMP, POPLIVE, Keychange; and to one industry-focused measuring exercise undertaken by a national trade body (UK Music's "Measuring Music" report). In the first 


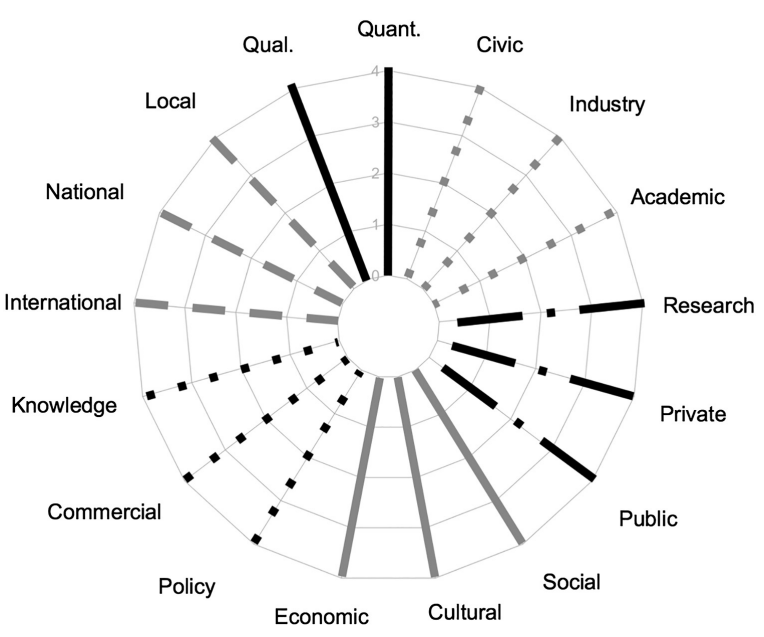

\section{CATEGORIES}

Data Methods Geographic Focus

Motivations

Research Focus

Funding

Actors

\section{SCALES}

\begin{tabular}{l|l}
4 (Max.) & 4 \\
3 (Major) & 3 \\
2 (Equal) & 2 \\
1 (Minor) & 1 \\
0 (None) & 0
\end{tabular}

Measuring the values of live music

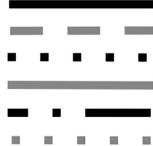

Figure 1.

Live music measurement model basic overview, including categories, scales and radar chart template showing 6 different groups and 17 sub-categories

visualisations below (figures 2-4), the three academic projects are shown in turn. Broadly, the projects produce a similar footprint on the radar chart, particularly in relation to funding and actors. The chart also highlights the difference in geographic focus between projects (BLMP and Keychange being more focussed on the Local in comparison to POPLIVE's National activity) and the comparatively stronger emphasis on Policy inherent in BLMP's research Motivations.

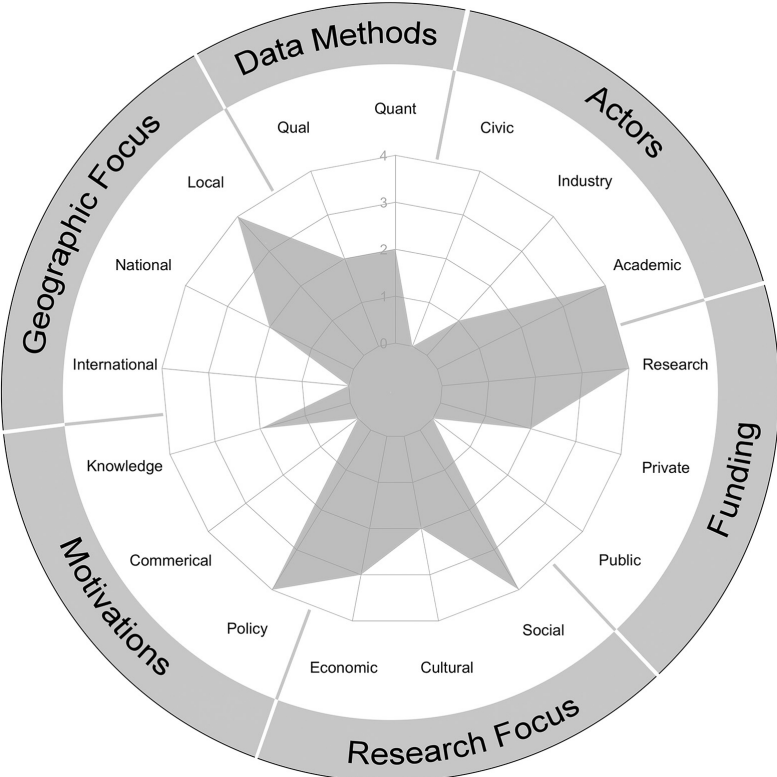

BLMP

Scales

$4 \operatorname{Max}$

3 Major

2 Equal

1 Minor

0 None

Figure 2.

Measuring music values model comparison of three recent academic measuring activities - BLMP 


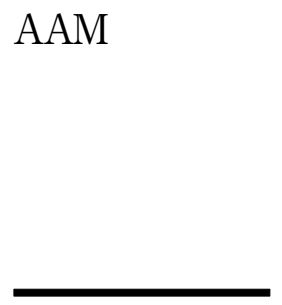

Figure 3.

Measuring music values model comparison of three recent academic measuring activities POPLIVE

Figure 4.

Measuring music

values model comparison of three recent academic measuring activities Keychange

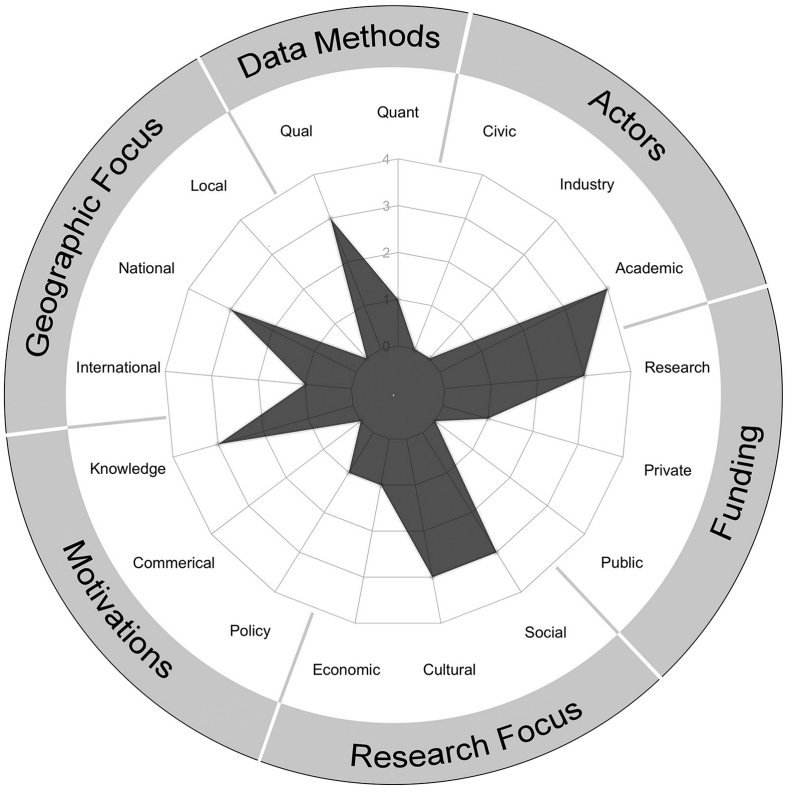

POPLIVE

Scales

4 Max

3 Major

2 Equal

1 Minor

o None

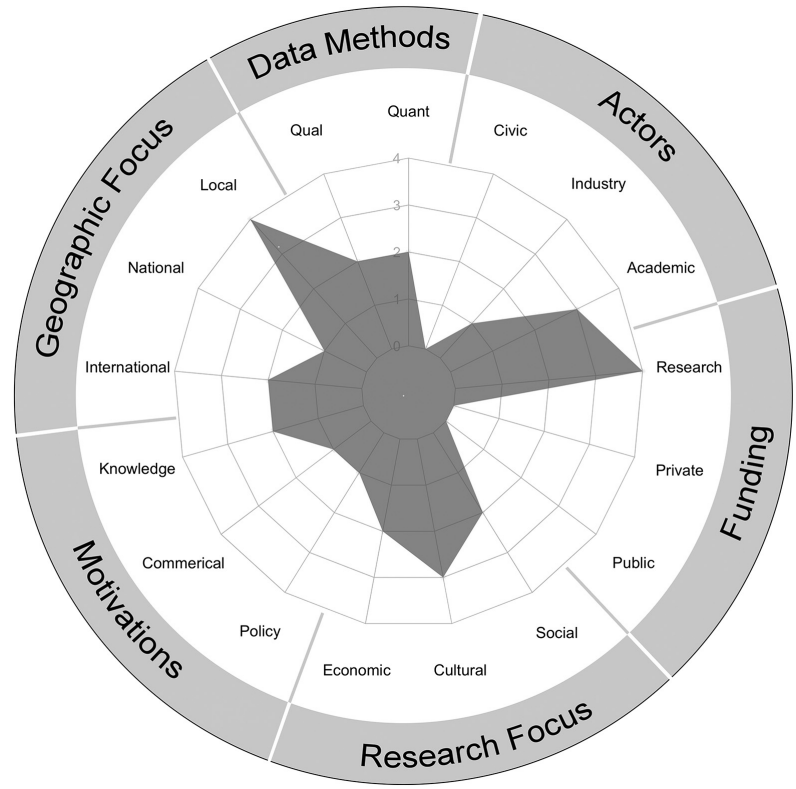

KeyChange

Scales

$4 \operatorname{Max}$

3 Major

2 Equal

1 Minor

o None

In the second set of visualisations (Figures 5 and 6), the scale values allocated to the three projects shown in Figures 2-4 are combined to create a mean "footprint" for academic work (Figure 5). This is then visualised next to an industry-led project (UK Music, Figure 6). These visualisations demonstrate the differences and similarities between projects in terms of 


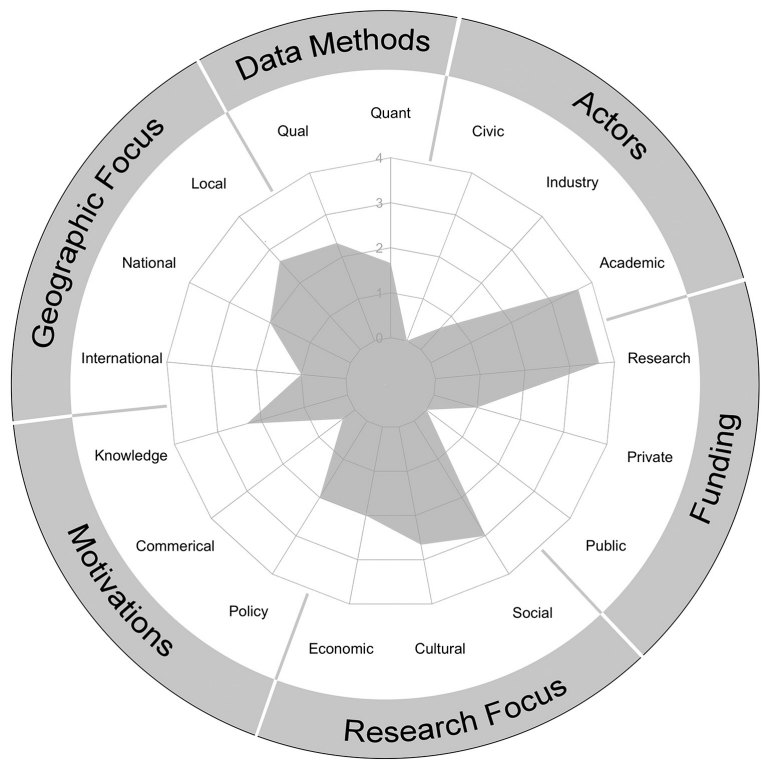

\section{Academic Research (Mean)}

Measuring the
values of live
music

Scales

$4 \operatorname{Max}$

Figure 5.

Measuring music

3 Major

values model .

comparison between 3

2 Equal

1 Minor

o None

academic measuring projects - shown here according to mean values applied to model scale for 17 elements

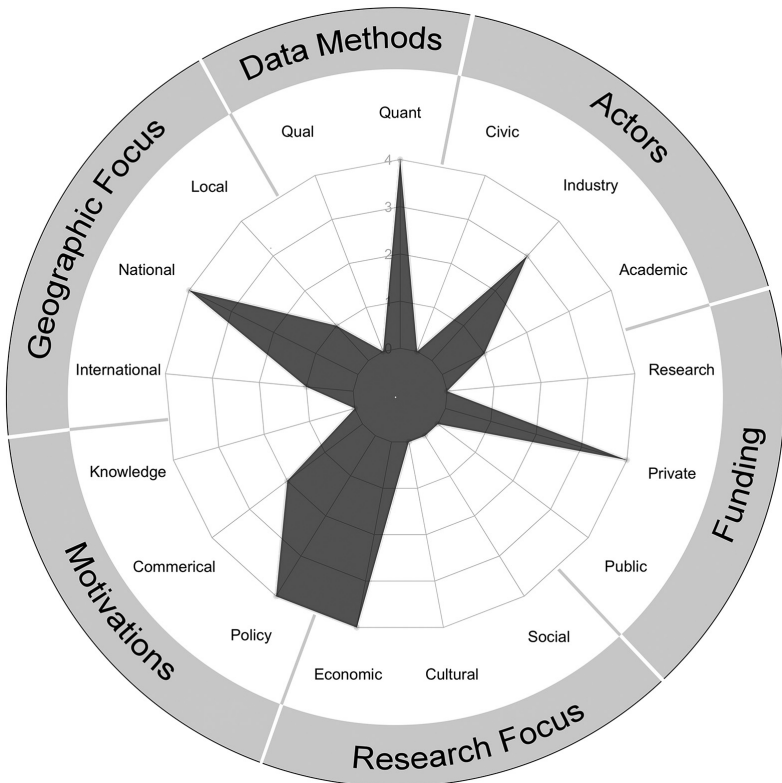

UK Music

Scales

$4 \operatorname{Max}$

3 Major

Figure 6.

Measuring music

2 Equal "Measuring Music" 1 Minor report prepared by UK o None industry trade body, UK Music

funding, actors, motivations, geographic focus, research focus and data methods. There is quite a distinctive pattern and similarity between academic research projects, especially with regard to sources of funding and research focus, which puts it in striking contrast to commercially-funded UK Music research, which prioritises an economic focus. However, 
there are also similarities. In particular, all examples focus on regional and/or national levels only. Furthermore, there is a degree of commonality in terms of motivations (policy), although this element is much stronger in the UK Music report. In our theoretical exercise, the visualisations clearly demonstrate gaps in research.

These models present two questions: how might each project learn from the others in terms of how they approached their common motivations and - perhaps more provocatively - how might the outcomes of each project have been different - or otherwise augmented - if some or all of the combinations of data methods, funding routes, etc. were reversed or reconfigured? Through our model, we are engaging here with the idea that certain types of research produce certain types of conceptions of live music ecologies. This, in turn, leads to a speculative question we hope to consider through further research and development of the model: what new or different types of live music ecologies may be produced by the alteration of commonly-used processes, or experimentation with hybrid processes revealed by other areas of the model?

Clearly, the model we have presented is not without limitations and is intended as an initial, exploratory work-in-progress. Certain segments (funding, actors, geographic focus) are relatively easy to compile since they involve practicalities. Others, and in particular motivations and research focus, reduce complex and contingent elements in ways that are likely inadequate (Berry, 2011a). In terms of how the model is visualised, the radar chart in particular is not without its limitations and-more broadly - research activity of this kind is the subject of much critique and debate (Caplan, 2016; Kitchin, 2014). Modifications to the model will therefore become the focus of our future work. The range of scale value allocation has so far been kept deliberately small, but has the potential to increase as we refine and operationalise the process of categorisation. Similarly, reducing activity to six segments does not allow for a great degree of nuance, but the model structure is intended to allow for new segments (and sub-categories within them) to be added or existing ones removed/retooled.

In presenting this initial model, we suggest that it has - subject to further development the potential to enhance understanding and best practice in live music research. It affords the opportunity to develop ways of effectively evaluating research that are specific to live music, with the aim that research has greater beneficial impact for the stakeholders concerned. Relatedly, by revealing how (and why and by whom) live music research is currently undertaken, the model acts as a resource for those planning new research projects. Here, we envisage it as a "field guide" and a starting point for the sharing of best practice. For example, data collection methodologies revealed by the model as a likely "fit" for a particular research aim, or location, can be identified, adapted and shared. This is pertinent to Sandvig and Hargittai's call for researchers to "reveal the messy details of what they are actually doing, aiming towards mutual reflection, creativity, and learning that advances the state of the art" (2015, p. 5). Further, the model may also reveal gaps in terms of under-researched areas, or else the potential for the deployment of alternative methodologies for existing measurement activity. Commonality of approach in - say - studies exploring the economic activity of a given city, may thus be considered not as accepted ways of undertaking research, but rather explored critically as methods that can/may only produce particular types of outcomes in terms of results and recommendations.

\section{Conclusions}

In this paper we have explored different methodologies for measuring the values of live music and the motivations of organisations engaged in that work. The values of live music and the attention for measuring cultural activities in general, have received increasing attention. Yet, we conclude that measuring live music is a complex, multi-faceted phenomenon. 
This complexity is enhanced by the fact that measuring live music is not a neutral activity, but itself constructs a vision on how live music ecologies ought to function.

First, we distinguish economic impact studies, in which live music is defined as a commodity. The vast majority of these studies focus on the external, direct economic impact of live music, although the indirect benefits also receive due attention. We find several disadvantages to this approach, including problems with getting access to data and incompleteness of data (e.g. missing data from "underground" grassroots supply, secondary ticketing and supply chains). Also, we find two contradictions in measuring the economic impact of live music: (1) in both industry and policy making, an increasing interest is attached to economic impact studies although these often appear to be complex, incomplete and in some cases unreliable; (2) live music is increasingly reduced to a commodity while several scholars emphasise the fact that cultural supply cannot be explained by classic economics. Some even state that such measuring practices are threatening the autonomy of the arts and creativity (Gielen et al., 2014).

The second approach we identify is maps and censuses, which form a spatial inventory (or snapshot) of live music practice. This is in most cases applied by academics, using quantitative techniques in order to gain unique insights in the geography of live music. The outcomes benefit (urban) cultural policy makers in particular, mainly due to the locality of the results. The cons of this methodology are that it depends heavily on availability of information and the (local) willingness to cooperate, and that it is hard to apply on a large scale. Third, SSH approaches put an emphasis on live music's impact on people and communities. In this case, (commissioned) academics apply both qualitative and quantitative techniques in their attempts to explain live music as a manifestation of culture. This academic research is vital to apply new theoretical and methodological innovations to the measurement of live music's values. All three discussed methodologies provide valuable insights to the field of live music, although they all deal with issues of (the reliability of) measurement.

We identify three groups of actors measuring the value of live music: industry, academia and policy. The industry actors regularly focus on economic studies and use the outcomes to legitimise their value and enhance their position in the policymaking process. One pitfall here is that the perceived methodological efficacy of economic impact studies is sometimes overstated. Live music studies in the academic world predominantly focus on SSH methodologies and in some cases also on economic studies. The main objective is to better understand live music as a cultural practice. Increasingly, academics attempt to valorise their research by cooperating more closely with industry and policymakers. In this relation between academics and industry, we found both tensions and synergies. Cultural policy actors have a strategic, long-term and often holistic approach to live music. In doing so, they cooperate with both industry and academics although this seems to differ per country. In the UK the cooperation between academics and policy seems to be better established than in The Netherlands.

Based on our findings, we developed an exploratory model for measuring the various values of live music. This model helps to evaluate research with a focus on live music, to reveal gaps in current practices, to identify the complex nature and sensitive position of live music research, to foster mutual reflection, creativity and learning and to find ways for alternative epistemologies and approaches in order to measure the impacts of live music in a more holistic way. Furthermore, the model opens up a discussion about the extent to which all actors are involved in the measuring and it highlights the potential of participatory approaches (e.g. BLMP).

Our analysis and model demonstrate that measuring live music's impact is a complex activity that should be understood in terms of how a wide array of factors inter-relate in any given project. This underscores the importance of looking in a holistic manner at the interconnections between organisations that measure the values of live music and actors in
Measuring the values of live music 
the music industry. Even if we move beyond the meta critique that cultural, artistic supply cannot be measured and that the consequences of cultural engagement are too remote in time and space to be a matter of simple cause and effect, we still find several issues of complexity. The producers and users of live music research are heavily intertwined, as they are all actors within the same ecology. Currently, live music research lacks epistemological and methodological common ground. The research approaches we presented in this paper are to a large extent carried out separately with a result that even methodologically robust measurements will have deficiencies. For example, the actors in the margins of live music ecologies tend to fall out of the scope of measurements. For this reason we advocate a more holistic and integrated view on measuring the values of the live music ecology; we would suggest to facilitate more cross-disciplinary research. We also suggest the application of technological advances to discover new ways of measuring live music's impact. Developments in big data could lead to new insights on how different actors in the live music ecology engage with live music and its materiality. Here, Music Data Observatory [6] seems a potentially useful initiative that is collaborative, automated and research-based. Industry actors such as streaming services and live music companies have a wealth of data that could be relevant to the fields of policy and academia as well. If more of this data would be accessible as Open Data, it would be easier to (re-)analyse it without any restrictions such as copyright. Furthermore, the application of artificial intelligence techniques (e.g. motion capture as applied in Swarbrick et al., 2019) could help in developing new research territories. As our experience of live music will increasingly rely on new digital technologies, the same will be the case for measures of its impact.

\section{Notes}

1. https://www.poplive.nl/

2. https://livemusicresearch.org/birmingham-live-music-project/

3. http://uklivemusiccensus.org/

4. https://www.seattle.gov/filmandmusic/music/seattle-music-then-and-now/music-map-brochure

5. http://www.seattlebandmap.com/blog/about/

6. https://dataobservatory.eu/post/2020-09-15-music-observatory-launch/

\section{References}

Andersson, T.D., Armbrecht, J. and Lundberg, E. (2012), "Estimating use and non-use values of a music festival", Scandinavian Journal of Hospitality and Tourism, Vol. 12 No. 3, pp. 215-231.

Angelini, F. and Castellani, M. (2018), "Cultural and economic value: a critical review", Journal of Cultural Economics, Vol. 43, pp. 173-188.

Bain, V. (2019), "Counting the music industry: the gender gap”, available at: https://countingmusic.co.uk (accessed 24 September 2020).

Behr, A. and Cloonan, M. (2018), "Going spare? Concert tickets, touting and cultural value", International Journal of Cultural Policy, Vol. 26 No. 1, pp. 95-108, doi: 10.1080/10286632.2018. 1431224 .

Behr, A., Brennan, M., Cloonan, M., Frith, S. and Webster, E. (2016), "Live concert performance: an ecological approach”, Rock Music Studies, Vol. 3 No. 1, pp. 5-23, doi: 10.1080/19401159.2015. 1125633.

Behr, A., Webster, E., Brennan, M., Cloonan, M. and Ansell, J. (2019), "Making live music count: the UK live music census”, Popular Music and Society, Vol. 43 No. 5, pp. 501-522, doi: 10.1080/03007766. 2019.1627658. 
Belfiore, E. (2002), "Art as a means of alleviating social exclusion: does it really work? A critique of instrumental cultural policies and social impact studies in the UK", International Journal of Cultural Policy, Vol. 8 No. 1, pp. 91-106, doi: 10.1080/102866302900324658.

Belfiore, E. and Bennett, O. (2010), "Beyond the 'toolkit approach': arts impact evaluation research and the realities of cultural policy-making", Journal for Cultural Research, Vol. 14 No. 2, pp. 121-142, doi: $10.1080 / 14797580903481280$.

Bennett, L. (2012), "Patterns of listening through social media: online fan engagement with the live music experience", Social Semiotics, Vol. 22 No. 5, pp. 545-557.

Berry, J. (2011), "Culture crash: organisational change in the cultural and creative industries in the North East of England", Paper Presented at the RSA Annual International Conference, Newcastle Upon Tyne, 17-20 April 20.

Berry, D.M. (2011a), "The computational turn: thinking about the digital humanities", Culture Machine, Vol. 12, pp. 1-22.

Caplan, L. (2016), "Method without methodology: data and the digital humanities", e-Flux Journal, Vol. 72, pp. 1-6.

Carter, D. and Muller, P. (2015), "The economic and cultural value of live music in Australia 2014", University of Tasmania, Australian Live Music Office, South Australian government City of Sydney: City of Melbourne and Live Music Office (Australia), available at: http://livemusicoffice. com.au/research/download-report/ (accessed 7 December 2020).

Cohen, S. (2012a), "Bubbles, tracks, borders and lines: mapping music and urban landscape", Journal of the Royal Musical Association, Vol. 137 No. 1, pp. 135-170, doi: 10.1080/02690403.2012. 669939.

Cohen, S. (2012b), "Live music and urban landscape: mapping the beat in Liverpool", Social Semiotics, Vol. 22 No. 5, pp. 587-603, doi: 10.1080/10350330.2012.731902.

Connolly, M. and Krueger, A. (2006), "Rockonomics: the economics of popular music", Handbook on the Economics of Art and Culture, Vol. 1, pp. 667-719.

Crossick, G. and Kaszynska, P. (2016), "Understanding the value of arts and culture. The AHRC cultural value project", Published by Arts and Humanities Research Council, available at: https://ahrc.ukri. org/documents/publications/cultural-value-project-final-report/ (accessed 25 November 2020).

Crossley, N. and Emms, R. (2016), "Mapping the musical universe: a blockmodel of UK music festivals, 2011-2013”, Methodological Innovations, Vol. 9, pp. 1-14, doi: 10.1177/2059799116630663.

Danielsen, A. and Kjus, Y. (2019), "The mediated festival: live music as trigger of streaming and social media engagement", Convergence: The International Journal of Research Into New Media Technologies, Vol. 25 No. 4, pp. 714-734, doi: 10.1177/1354856517721808.

Dyndahl, P. (2013), "Musical gentrification, socio-cultural diversities, and the accountability of academics", in Dyndahl, P. (Ed.), Intersection and Interplay. Contributions to the Cultural Study of Music in Performance, Education and Society, Malmö Academy of Music, Lund University, Malmö, pp. 173-188.

Everts, R., Hitters, E. and Berkers, P. (forthcoming), "The working life of musicians: mapping the work activities and values of early-career pop musicians in the Dutch music industry", Creative Industries Journal.

Garretsen, H. and Marlet, G. (2017), “Amenities and the attraction of Dutch cities”, Regional Studies, Vol. 51 No. 5, pp. 724-736, doi: 10.1080/00343404.2015.1135239.

Getz, D., Andersson, T., Armbrecht, J. and Lundberg, E. (2017), "Definitions and meanings of value", in Lundberg, E., Armbrecht, J., Andersson, T. and Getz, D. (Eds), The Value of Events, Routledge, London, pp. 1-9.

Gielen, P., Elkhuizen, S., van den Hoogen, Q., Lijster, T. and Otte, H. (2014), De Waarde Van Cultuur, Rijksuniversiteit Groningen, Onderzoekscentrum Arts in Society, Groningen.

Gitelman, L. (2013), Raw Data Is an Oxymoron, MIT press, Cambridge, Massachusetts, MA. 
Greater London Authority (2015), “London's grassroots music venues rescue plan”, available at: https://www.london.gov.uk/sites/default/files/londons_grassroots_music_venues_-_rescue_ plan_-_october_20152.pdf (accessed 30 September 2020).

House of Commons Digital, Culture, Media and Sport Committee (2019), Live Music: Ninth Report of Session 2017-19, House of Commons, London, available at: https://publications.parliament.uk/ $\mathrm{pa} / \mathrm{cm} 201719 / \mathrm{cmselect} / \mathrm{cmcumeds} / 733 / 733 . p d f$ (accessed 28 September 2020).

House of Commons Digital, Culture, Media and Sport Committee (2020), Impact of COVID-19 on DCMS Sectors: First Report. Third Report of Session 2019-2021, House of Commons, London, available at: https://committees.parliament.uk/publications/2022/documents/19516/default/ (accessed 24 September 2020).

Holden, J. (2004), Capturing Cultural Value, Demos, London.

Holt, F. (2010), "The economy of live music in the digital age", European Journal of Cultural Studies, Vol. 13 No. 2, pp. 243-261, doi: 10.1177/1367549409352277.

Kitchin, R. (2014), "Big Data, new epistemologies and paradigm shifts", Big Data and Society, Vol. 1 No. 1 , pp. 1-12.

Klamer, A. (2004), "Cultural goods are good for more than their economic value", in Rao, V. and Walton, M. (Eds), Culture and Public Action, Stanford University, Palo Alto, pp. 138-162.

Krueger, A.B. (2019), Rockonomics: A Backstage Tour of What the Music Industry Can Teach Us About Economics And Life, Currency, New York, NY.

Lashua, B. and Cohen, S. (2010), "Liverpool music scapes: music performance, movement and the built urban environment", in Fincham, B., McGuinness, M. and Murray, L. (Eds), Mobile Methodologies, Palgrave Macmillan, London. doi: 10.1057/9780230281172_6.

Leenders, M.A.A.M. (2010), "The relative importance of the brand of music festivals: a customer equity perspective", Journal of Strategic Marketing, Vol. 18 No. 4, pp. 291-301, doi: 10.1080/ 09652541003768061.

Mattioli, C. (2014), "Crowd sourced maps: cognitive instruments for urban planning and tools to enhance citizens' participation", in Contin, A., Paolini, P. and Salerno, R. (Eds), Innovative Technologies in Urban Mapping, Springer International Publishing, New York, NY, pp. 145-156.

Mercado-Celis, A. (2017), "Districts and networks in the digital generation music scene in Mexico city", Area Development and Policy, Vol. 2 No. 1, pp. 55-70, doi: 10.1080/23792949.2016.1248455.

Mortimer, J., Nosko, C. and Sorensen, A. (2012), "Supply responses to digital distribution: recorded music and live performances", Information Economics and Policy, Vol. 24 No. 1, pp. 3-14.

Mulder, M., Hitters, E. and Rutten, P. (2020), "The impact of festivalization on the Dutch live music action field: a thematic analysis", Creative Industries Journal, Advance online publication. doi: 10.1080/17510694.2020.1815396.

Musicians' Union (2020), "Coronavirus presses mute button on music industry”, 22 September, available at: https://www.musiciansunion.org.uk/Home/News/2020/Sep/Coronavirus-PressesMute-Button-on-Music-Industry (accessed 24 September 2020).

Naveed, K., Watanabe, C. and Neittaanmäki, P. (2017), "Co-evolution between streaming and live music leads a way to the sustainable growth of music industry - lessons from the US experiences", Technology in Society, Vol. 50, pp. 1-19. doi: 10.1016/j.techsoc.2017.03.005.

O'Brien, D. (2010), Measuring the Value of Culture: A Report to the Department for Culture Media and Sport, DCMS, London, available at: https:/www.gov.uk/government/uploads/system/uploads/ attachment_data/file/77933/measuring-the-value-culture-report.pdf (accessed 19 June 2020).

Packer, J. and Ballantyne, J. (2011), “The impact of music festival attendance on young people's psychological and social well-being", Psychology of Music, Vol. 39 No. 2, pp. 164-181.

Propheter, G. (2015), "Frequency and attendance at popular music concerts in the USA: does facility age matter?", Cultural Trends, Vol. 24 No. 4, pp. 310-319, doi: 10.1080/09548963.2015. 1088122. 
Raine, S. (2019), "Keychanges at Cheltenham Jazz festival: issues of gender in the UK Jazz scene", in Strong, C. (Ed.), Towards Gender Equality in the Music Industry: Education, Practice and Strategies for Change, Bloomsbury Publishing Inc, London, pp. 187-200.

Rozbicka, P., Hamilton, C., Behr, A., Correa, P. and Davies, L.J. (2019), Birmingham Live Music and Brexit: Report I, Aston University, Birmingham City University and Newcastle University, Birmingham, available at: https://www2.aston.ac.uk/lss/research/lss-research/aston-centreeurope/projects-grants/blmp-report-i.pdf (accessed 7 December 2020).

Sandvig, C. and Hargittai, S. (2015), "How to think about digital research", in Hargittai, S. and Sandvig, C. (Eds), Digital Research Confidential: The Secrets of Studying Behavior Online, MIT Press, Cambridge, Massachusetts, MA, pp. 1-25.

Southall, H.V. (2016), "Dance bands in Chester and North Wales, 1930-1970: revealing a hidden history”, Paper Presented at The Hidden Musicians Revisited Conference, Milton Keynes, 11-12 January, Open University, available at: https://chesterrep.openrepository.com/handle/10034/ 612346 (accessed 19 June 2020).

Swarbrick, D., Bosnyak, D., Livingstone, S.R., Bansal, J., Marsh-Rollo, S., Woolhouse, M.H. and Trainor, L.J. (2019), "How live music moves us: head movement differences in audiences to live versus recorded music", Frontiers in Psychology, Vol. 9, pp. 1-11, doi: 10.3389/fpsyg.2018.02682.

UK Music (2015), "Wish You were here 2015: the contribution of live music to the UK economy. Methodology", available at: https://www.ukmusic.org/assets/general/WYWH_METHODOLOGY 2015.pdf (accessed 24 September 2020).

UK Music (2017), "Wish you were here 2017: the contribution of live music to the UK economy", available at: https:/www.ukmusic.org/assets/general/Report_WYWH_17.pdf (accessed 24 September 2020).

UK Music (2019), “Music by numbers 2019”, available at: https:/www.ukmusic.org/research/music-bynumbers/ (accessed 24 September 2020).

UK Music (2020), “COVID-19. Policy and campaigns”, available at: https://www.ukmusic.org/covid-19/ policy-campaign (accessed 24 September 2020).

UNESCO (2009), "Festival Statistics: key concepts and practices”, available at: http://uis.unesco.org/ sites/default/files/documents/festival-statistics-key-concepts-and-current-practices-handbook-32015-en.pdf (accessed 26 September 2020).

Velthuis, O. (2005), Talking Prices: Symbolic Meanings of Prices on the Market for Contemporary Art, Princeton University Press, New Jersey, NJ.

VNPF (2018), Poppodia en -festivals in cijfers 2018”, Vereniging Nederlandse Poppodia en - Festivals (VNPF), Amsterdam, available at: https:/vnpf.nl/media/files/vnpf-poppodia-en-festivals-incijfers-2018.pdf (accessed 29 September 2020).

Wall, T. (2008), "Making money out of music: the role of music and radio in regional economic development”, BOX 1:07, available at: https://wallofsound.files.wordpress.com/2007/07/box_1_ 07.pdf (accessed 24 September 2020).

Waterson, M. (2016), Independent Review of Consumer Protection Measures Concerning Online Secondary Ticketing Facilities, Department for Business, Innovation and Skills, London.

Webster, E. (2011), "Promoting live music in the UK: a behind-the-scenes ethnography", PhD thesis, University of Glasgow, Glasgow.

Webster, E., Brennan, M., Behr, A., Cloonan, M. and Ansell, J. (2018), "Valuing live music: the UK live music census 2017 report”, Live Music Exchange, University of Edinburgh/Newcastle University/University of Turku, Edinburgh.

Willekens, M. and Daenekindt, S. (2020), "Cultural logics and modes of consumption: unraveling the multiplicity of symbolic distinctions among concert audiences”, Musicae Scientiae, advance online publication. doi: 10.1177/1029864920908305.

Williamson, J. and Cloonan, M. (2007), "Rethinking the music industry", Popular Music, Vol. 26 No. 2 , pp. 305-322.
Measuring the values of live music

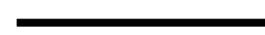


Williamson, J., Cloonan, M. and Frith, S. (2011), "Having an Impact? Academics, the music industries and the problem of knowledge", International Journal of Cultural Policy, Vol. 17 No. 5, pp. 459-474.

\section{Corresponding author}

Arno van der Hoeven can be contacted at: vanderhoeven@eshcc.eur.nl

For instructions on how to order reprints of this article, please visit our website: www.emeraldgrouppublishing.com/licensing/reprints.htm Or contact us for further details: permissions@emeraldinsight.com 